\title{
IMPACT OF SPECIAL AVIATION GYMNASTICS INSTRUMENTS TRAINING ON SELECTED HORMONES IN CADETS' BLOOD SERUM AND PLASMA
}

\section{ZBIGNIEW WOCHYŃSKI ${ }^{1}$ and KRZYSZTOF SOBIECH ${ }^{2}$}

\author{
${ }^{1}$ Polish Air Force Academy, Dęblin, Poland \\ Department of Physical Education \\ ${ }^{2}$ University School of Physical Education, Wrocław, Poland \\ Department of Human Biology
}

\begin{abstract}
Objectives: This study has aimed at investigating the impact of the Special Aviation Gymnastics Instruments (SAGI) training scheme on the blood serum cortisol, testosterone, insulin, and plasma adrenaline, noradrenaline, and dopamine in comparison with a control group. Material and Methods: Fifty-five cadets, aged 20 years old, participated in the study. Cadets were divided into 2 groups: A $(\mathrm{N}=41)$ - the SAGI-trained, and $\mathrm{B}(\mathrm{N}=14)$ - the control group. In both groups, blood was the examined material, sampled twice: before the training session (BT) and after the training session (AT), at the beginning (training session I), during (training session II), and after completion of the SAGI training session (training session III). Commercially available kits were used for assaying serum cortisol, testosterone, and insulin as well as plasma adrenaline, noradrenaline, and dopamine. Cadets' physical fitness was assessed by means of Aero-Synthetic Efficiency Tests. Results: In group A, a significant decrease in serum cortisol (training session III) and insulin in three training sessions AT in comparison with the values BT was seen. A statistically significant increase in testosterone and catecholamines was noted in all 3 training sessions AT in comparison with the values BT. In group B, a statistically significant increase in cortisol (training session II), testosterone, and catecholamines was observed in all 3 training sessions AT vs. the values in training session BT. In group B, serum levels of all assayed hormones were higher in training session III than those in group A. Conclusions: In the examined group, the SAGI training produced fewer hormonal changes dependent on the intensity and exercise type and physical efficiency improvement than in the control group. Int J Occup Med Environ Health 2017;30(4):655-664
\end{abstract}

Key words:

Special Aviation Gymnastics Instruments, Cortisol, Testosterone, Insulin, Adrenaline, Noradrenaline

\section{INTRODUCTION}

The Special Aviation Gymnastics Instruments (SAGI) training scheme prepares the body to extreme conditions of pilots' work. The Special Aviation Gymnastics Instruments include: a gyroscope, aero wheel, and looping. Specificity of the training scheme and types of those instruments have been described in the previous study [1]. Blood hormones are worth special attention in the physical effort diagnosis because of their regulation function in the body. Hormones belong to the markers

Funding: this study was financed by the grants for 2009-2010 as a developmental project entitled "Training system for improving balance and visual-motor coordination of multirole aircraft pilots" No. O R/00 001706. Grant manager: Marek Grzegorzewski, Ph.D.

Received: January 25, 2016. Accepted: June 28, 2016.

Corresponding author: Z. Wochyński, Polish Air Force Academy, Department of Physical Education, 12 Dywizjon 303 Street, 08-521 Dęblin, Poland (e-mail: zbigniew. wochynski@op.pl). 
indicating readiness for physical work increase or decrease. Therefore, the relationship and conditions of hormones release in various types of physical work are constantly sought.

Following hormones are most frequently used for measuring physical effort intensity in the case of athletes: testosterone, cortisol, and insulin. They serve the purpose of evaluation of anabolic-catabolic equilibrium for the athletes during exercises [2-4]. Catecholamines (adrenaline, noradrenaline, dopamine) are known as stress hormones and their blood levels depend on the exercise intensity. Catecholamines coordinate functioning of the nervous system and endocrine glands. The most important reports have shown that physical effort increases blood serum testosterone and cortisol, and decreases serum insulin. Secretion of the counterregulatory hormones such as adrenaline, noradrenaline, and cortisol is increased [5-7]. Use of these hormones for evaluation of the impact of the SAGI training on the cadets' bodies enables to increase diagnostic value in the evaluation of the body load and adaptation. Prolonged exercise stimulus (without a proper control) may inhibit adaptation processes, decrease in efficiency and metabolic disorders. Stress related to the specific exercises to the extent of the SAGI may disturb body equilibrium.

In the available subject literature, there are no reports on the changes in these hormones levels in both blood serum and plasma produced by the SAGI training, while such a training may produce changes similar to those seen in the master athletes. Seeking comparisons of the hormonal changes produced by the physical exercises may play a practical role in the aviation. Therefore, the authors attempt to evaluate exercise load produced by the SAGI training with the aid of the following hormones assays in the blood serum: cortisol, testosterone, insulin, and plasma adrenaline, noradrenaline, and dopamine.

In this study a hypothesis has been put forward that the SAGI exercise may improve physical fitness of cadets and cause post-exercise changes in the concentration of cortisol, more dependent on the type than on the intensity of exercises. The aforementioned changes also concern the concentration of testosterone, insulin, dopamine, epinephrine and norepinephrine depending on the intensity of exercise in comparison to the control group.

\section{MATERIAL AND METHODS \\ Subjects}

The study involved 55 cadets, males aged approx. 20 years old, body weight between $67.59-71.03 \mathrm{~kg}$, height between 173.64-176.64 cm, and body mass index (BMI) between $22.49-22.82 \mathrm{~kg} / \mathrm{m}^{2}$ (Table 1). Participants were divided into 2 groups: the examined group $A(N=41)$ realizing the SAGI scheme [1], and the control group B $(\mathrm{N}=14)$ realizing a standard program of physical education. In both groups, the material for assays was blood collected twice before the training session (BT) and after the training session (AT) at the beginning (training session I), during (training session II), and after completion of the SAGI training scheme (training session III).

\section{Blood collection}

Blood samples were collected before the training session in all 3 training sessions, at 9:00 a.m., i.e., $2 \mathrm{~h}$ after breakfast, and immediately after the training session at 11:00 a.m. Duration of the physical education program consisted of 20 training units of $2 \mathrm{~h}$ for 70 days.

\section{Hormone assays}

Serum cortisol, testosterone, and insulin were assayed by means of the electrochemiluminescence technique, using the reagents made by Roche and Cobas 6000 analyzer. Plasma adrenaline, noradrenaline, and dopamine were assayed by high pressure liquid chromatography with electrochemical detection (HPLC/EC), Amersham reagents, and GILSON devices. 
Table 1. Demographic data and the heart rate in the studied groups - SAGI-trained cadets (group A) and control (group B) [1,10]

\begin{tabular}{lrrr}
\hline & Group A & Group B & \\
& $\begin{array}{r}(\mathrm{N}=41) \\
(\mathrm{M} \pm \mathrm{SD})\end{array}$ & $\begin{array}{c}(\mathrm{N}=14) \\
(\mathrm{M} \pm \mathrm{SD})\end{array}$ & n.s. \\
\hline Age [years] & $20.53 \pm 1.02$ & $20.21 \pm 0.42$ & n.s. \\
Height $[\mathrm{cm}]$ & $176.64 \pm 5.78$ & $173.62 \pm 5.12$ & n.s. \\
Body weight $[\mathrm{kg}]$ & $71.03 \pm 6.94$ & $67.59 \pm 6.36$ & n.s. \\
BMI $\left[\mathrm{kg} / \mathrm{m}^{2}\right]$ & $22.82 \pm 1.95$ & $22.49 \pm 1.87$ & \\
HR [bpm] from the training unit & & & $<0.001$ \\
$\quad$ training I & $108.5 \pm 11.80$ & $131.6 \pm 15.80$ & $<0.001$ \\
$\quad$ training II & $107.3 \pm 11.70$ & $139.7 \pm 8.80$ & $<0.001$ \\
$\quad$ training III & $101.7 \pm 7.69$ & $145.3 \pm 6.70$ & \\
\hline
\end{tabular}

SAGI - Special Aviation Gymnastics Instruments.

BMI - body mass index; HR - heart rate; M - mean; SD - standard deviation; n.s. - statistically non-significant.

\section{Training intensity assessment}

Polar Team-2 Pro system was used for measuring training intensity and its monitoring, registering heart rate (HR) changes. A strip with the HR register was attached at the chest level of the trained cadet. After training, the strip was detached and placed in the device reading HR changes.

\section{Ethical issues}

The authors obtained the permission of the appropriate ethical commission to perform the study. The consent of the proper bioethical commission for the studies was obtained (decision No. 03A/2009 of 8 July 2009 issued by the Ethical Commission on biomedical research studies at the Military Institute of Aviation Medicine in Warszawa). The study was conducted according to the ethical standards of the International Journal of Sports Medicine [8], and was approved by the local ethics committee.

\section{Procedure and design}

Training program

In group A in all 3 training sessions, the training stimulus was similar as far as intensity and exercise content are concerned. The training scheme was carried out by means of the interval method in all 3 training sessions. The training scheme consisted of the following consecutive exercises:

- Looping: 2 series of spins on blocked looping. Each series consisted of 10 spins forward and 10 spins backward. Interval between series lasted $20 \mathrm{~s}$ (Photo 1a). Pause before the next exercise on gyroscope lasted $3 \mathrm{~min}$.

- Gyroscope: 2 series of the dynamic turns, each of them lasting $60 \mathrm{~s}$. Interval between series lasted $20 \mathrm{~s}$ (Photo $1 b)$. Pause before the consecutive exercises on the aero wheel lasted $3 \mathrm{~min}$.

- Aero wheel: 2 series of turns. Each series consisted of 3 turns sideways to the right and 3 turns sideways to the left. Each series was repeated 4 times of 3 turns in alternating direction (Photo 1c). Interval between series
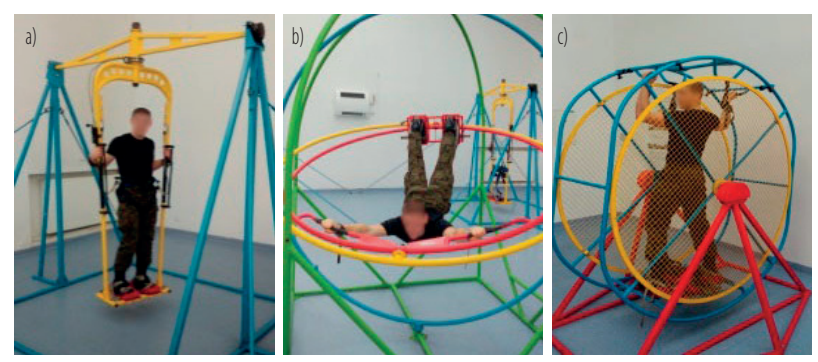

Photo 1. Special Aviation Gymnastics Instruments:

a) looping, b) a gyroscope, c) an aero wheel 
lasted $20 \mathrm{~s}$. Pause before the next exercises on the detached aero wheel lasted $3 \mathrm{~min}$. The above mentioned exercises were repeated thrice on each instrument.

\section{Standard program of physical education}

In group B, exercises of similar intensity were performed in all three training sessions. Physical education program included exercises improving the general physical fitness with an emphasis on all motor capabilities (standard team sports, light athletics, gymnastics, outdoor runs). Intensity of all exercises was quite high to increase body functional abilities and adapt to higher load in the further stage of the education. The so called goal technique, repetitions, and interval techniques were used during the training sessions.

In both groups, apart from different training programs, the same all-day physical activity including drill, march, and other military activities in the period of the experiment were done additionally.

All cadets' physical fitness was evaluated prior to (series I) and after completion (series II) of the study with physical efficiency tests such as: the Aero-Synthetic Efficiency Test (ASET) [9], shuttle run $10 \times 10 \mathrm{~m}$, pulling up on the horizontal bar, and trunk bends.

During the education program, all participants had identical living condition and nutrition. A standard diet was provided. Daily diet contained $4500 \mathrm{kcal}$ on the average, including $150 \mathrm{~g}$ of fat (30\%), $112.5 \mathrm{~g}$ of protein (10\%), and $675 \mathrm{~g}$ of carbohydrates $(60 \%)$.

\section{Statistical analysis}

In the statistical analysis, average values and standard deviations were calculated for all investigated hormones. All data sets were tested for normal distribution according to the Kolmogorov-Smirnov test, while Levene's test was used for verifying homogeneity of variances. Differences in hormones concentration before and after the training session were calculated by means of the T-test for dependent groups whereas between groups - by the analysis of variances (ANOVA). For the purpose of the statistical analysis of the obtained results, the program named Statistica 9.0 was used. The differences in the average values are considered significant, when the calculated p-value is below 0.05 .

\section{RESULTS}

No statistically significant difference was found between both groups in regard to the age, body weight, height, and BMI values (Table 1). Heart rate recorded during the training units in all 3 training sessions showed statistically significantly higher increase in intensity in group B at $\mathrm{p}<0.001$ in comparison with group A.

In group $\mathrm{A}$, the obtained results indicated a significant decrease in serum cortisol in all 3 training sessions AT at $\mathrm{p}<0.01$ in comparison with BT values (Table 2). In group $\mathrm{B}$, a significant increase in AT cortisol values was noted in training session II at $\mathrm{p}<0.005$ vs. BT values (Table 3). It was found that serum cortisol AT values were significantly higher in training sessions II and III at $\mathrm{p}<0.005$ in comparison with group A (Table 3). There were no significant differences in the remaining assays.

In group A, the statistically significant increase in AT serum testosterone in all 3 training sessions was at $p<0.01$, $\mathrm{p}<0.001$, and $\mathrm{p}<0.001$, respectively, in comparison with BT values (Table 2). In group B, the significant increase in AT serum testosterone was found in all 3 training sessions at $\mathrm{p}<0.05$ in comparison with BT values (Table 3 ). In group $\mathrm{A}$, significantly higher values of both $\mathrm{BT}$ and $\mathrm{AT}$ serum testosterone in training session II at $\mathrm{p}<0.000$ and $\mathrm{p}<0.01$, respectively, than those in group B (Table 3). The remaining parameters did not differ significantly.

In group A, a decrease in AT serum insulin was seen in all 3 training sessions at $p<0.000$ in comparison with BT values (Table 2). In group $B$, the statistically significant decrease in AT serum insulin was also observed in all 3 training sessions at $\mathrm{p}<0.000, \mathrm{p}<0.01$, and $\mathrm{p}<0.01$, respectively, in comparison with BT values (Table 3). 
Table 2. Changes in the blood serum and plasma hormones before and after the Special Aerial Gymnastics Instruments (SAGI) training scheme in group A (SAGI-trained cadets, $\mathrm{N}=41$ ) in 3 training sessions

\begin{tabular}{|c|c|c|c|c|c|c|}
\hline \multirow{2}{*}{ Parameter } & \multicolumn{2}{|c|}{$\begin{array}{l}\text { Training session I } \\
\quad(\mathrm{M} \pm \mathrm{SD})\end{array}$} & \multicolumn{2}{|c|}{$\begin{array}{c}\text { Training session II } \\
\quad(\mathrm{M} \pm \mathrm{SD})\end{array}$} & \multicolumn{2}{|c|}{$\begin{array}{l}\text { Training session III } \\
\quad(\mathrm{M} \pm \mathrm{SD})\end{array}$} \\
\hline & BT & AT & BT & AT & BT & AT \\
\hline Cortisol [nmol/l] & $434.6 \pm 118.1$ & $412.1 \pm 152.5$ & $469.5 \pm 124.7$ & $438.2 \pm 164.1$ & $379.8 \pm 91.4$ & $317.1 \pm 125.8^{b}$ \\
\hline Testosterone $[\mathrm{nmol} / \mathrm{l}]$ & $18.2 \pm 3.6$ & $20.8 \pm 5.6^{\mathrm{b}}$ & $18.7 \pm 3.9$ & $21.5 \pm 4.5^{\mathrm{d}}$ & $16.7 \pm 3.0$ & $20.4 \pm 4.6^{\mathrm{d}}$ \\
\hline Insulin $[\mu \mathrm{U} / \mathrm{ml}]$ & $17.7 \pm 6.2$ & $8.3 \pm 3.1^{\mathrm{e}}$ & $16.3 \pm 5.1$ & $8.9 \pm 3.4^{\mathrm{e}}$ & $11.2 \pm 5.6$ & $5.7 \pm 2.9^{\mathrm{e}}$ \\
\hline Adrenaline $[\mathrm{ng} / \mathrm{l}]$ & $19.9 \pm 6.7$ & $25.2 \pm 8.8^{c}$ & $13.3 \pm 5.4$ & $18.3 \pm 8.9^{c}$ & $7.31 \pm 2.60$ & $11.46 \pm 4.61^{\mathrm{e}}$ \\
\hline Noradrenaline [ng/l] & $224.7 \pm 46.2$ & $276.1 \pm 63.6^{\mathrm{e}}$ & $196.5 \pm 94.1$ & $245.2 \pm 81.3^{c}$ & $132.1 \pm 74.9$ & $163.8 \pm 100.6^{\mathrm{a}}$ \\
\hline Dopamine $[\mu \mathrm{g} / 1]$ & $22.7 \pm 10.7$ & $32.6 \pm 18.3^{c}$ & $43.8 \pm 16.6$ & $78.8 \pm 56.1^{\mathrm{e}}$ & $52.3 \pm 21.3$ & $76.8 \pm 28.2^{\mathrm{e}}$ \\
\hline
\end{tabular}

I - at the beginning of the SAGI training session; II - during; III - after completion.

$\mathrm{BT}$ - before the training session; AT - after the training session.

Other abbreviations as in Table 1.

Difference statistically significant vs. BT value at: ${ }^{\mathrm{a}} \mathrm{p}<0.05 ;{ }^{\mathrm{b}} \mathrm{p}<0.01 ;{ }^{\mathrm{c}} \mathrm{p}<0.005 ;{ }^{\mathrm{d}} \mathrm{p}<0.001 ;{ }^{\mathrm{e}} \mathrm{p}<0.000$.

Table 3. Changes in the blood serum and plasma hormones before and after the Special Aerial Gymnastics Instruments (SAGI) training scheme in group B (control, $\mathrm{N}=14$ ) in 3 training sessions

\begin{tabular}{|c|c|c|c|c|c|c|}
\hline \multirow[t]{2}{*}{ Parameter } & \multicolumn{2}{|c|}{$\begin{array}{l}\text { Training session I } \\
\quad(\mathrm{M} \pm \mathrm{SD})\end{array}$} & \multicolumn{2}{|c|}{$\begin{array}{l}\text { Training session II } \\
\quad(\mathrm{M} \pm \mathrm{SD})\end{array}$} & \multicolumn{2}{|c|}{$\begin{array}{l}\text { Training session III } \\
\quad(\mathrm{M} \pm \mathrm{SD})\end{array}$} \\
\hline & BT & AT & BT & AT & BT & AT \\
\hline Cortisol [nmol/l] & $412.6 \pm 96.5$ & $358.6 \pm 97.7$ & $433.2 \pm 96.2$ & $578.7 \pm 136.0^{+c}$ & $376.7 \pm 137.7$ & $442.6+ \pm 140.2$ \\
\hline Testosterone $[\mathrm{nmol} / \mathrm{l}]$ & $18.1 \pm 5.0$ & $20.4 \pm 4.7^{\mathrm{a}}$ & $13.8 \pm 2.9^{\S}$ & $17.5 \pm 4.5^{* *_{\mathrm{a}}}$ & $16.8 \pm 5.1$ & $22.0 \pm 6.1^{\mathrm{a}}$ \\
\hline Insulin $[\mu \mathrm{U} / \mathrm{ml}]$ & $20.6 \pm 5.9$ & $7.5 \pm 2.8^{\mathrm{e}}$ & $17.9 \pm 6.4$ & $11.9 \pm 2.6^{+b}$ & $11.2 \pm 5.0$ & $7.2 \pm 1.9^{\mathrm{b}}$ \\
\hline Adrenaline [ng/l] & $31.0 \pm 13.4^{\S}$ & $52.5 \pm 11 . .^{\$ \S \mathrm{e}}$ & $13.1 \pm 2.7$ & $15.6 \pm 3.8^{\mathrm{a}}$ & $17.1 \pm 5.8^{\S}$ & $29.2 \pm 10.7 \$ s c$ \\
\hline Noradrenaline [ng/l] & $286.8 \pm 110.3^{* * *}$ & $386.5 \pm 107.0$ \$\$a & $107.8 \pm 30.0^{* * *}$ & $196.6 \pm 55.2^{* \mathrm{e}}$ & $253.2 \pm 75.4^{\S}$ & $356.8 \pm 175.7^{\$ \S \mathrm{a}}$ \\
\hline Dopamine $[\mu \mathrm{g} / \mathrm{l}]$ & $32.3 \pm 8.3^{* * *}$ & $46.4 \pm 14.2 * *_{c}$ & $34.7 \pm 11.8$ & $45.4 \pm 11.1^{* b}$ & $67.3 \pm 28.2^{\#}$ & $106.9 \pm 45.1^{* * \mathrm{c}}$ \\
\hline
\end{tabular}

Abbreviations as in Tables 1 and 2.

Difference statistically significant at: * $\mathrm{p}<0.05$ vs. AT value in group A; ${ }^{* *} \mathrm{p}<0.01$ vs. AT value in group A; *** $\mathrm{p}<0.005$ vs. BT value in group A; ${ }^{+} \mathrm{p}<0.005$ vs. AT value in group $\mathrm{A} ;{ }^{\#} \mathrm{p}<0.05$ vs. BT value in group $\mathrm{A} ;{ }^{\S} \mathrm{p}<0.000$ vs. BT value in group $\mathrm{A} ;{ }^{\S \S} \mathrm{p}<0.000$ vs. AT value in group A; ${ }^{\mathrm{a}} \mathrm{p}<0.05$ vs. BT value in group B; ${ }^{\mathrm{b}} \mathrm{p}<0.01$ vs. BT value in group $\mathrm{B} ;{ }^{\mathrm{c}} \mathrm{p}<0.005$ vs. BT value in group B; ${ }^{\mathrm{d}} \mathrm{p}<0.001$ vs. BT value in group B; ${ }^{\mathrm{e}} \mathrm{p}<0.000$ vs. BT value in group B.

Higher AT values were found in group B in training session II at $p<0.005$ than in group A. No statistically significant differences were noted in the remaining trainings. In group A, the statistically significant increase in AT plasma adrenaline was shown in all 3 training sessions at $\mathrm{p}<0.005$, $\mathrm{p}<0.005$, and $\mathrm{p}<0.000$, in comparison with BT values (Table 2). In group B, the statistically significant increase in AT plasma adrenaline was also found in all 3 training sessions at $p<0.000, p<0.05$, and $p<0.005$, respectively, in comparison with BT values (Table 3). In group B, both BT and AT values were significantly higher in training sessions I and III at $\mathrm{p}<0.000, \mathrm{p}<0.000$, and $\mathrm{p}<0.000$ than those in group A (Table 3). No statistically significant differences were noted in the remaining trainings. 
In group A, the statistically significant increase in AT plasma noradrenaline at $p<0.000, p<0.005$, and $p<0.05$, respectively, was noted in all three training sessions in comparison with BT values (Table 2). In group B, AT plasma noradrenaline increased statistically significantly at $p<0.005$, $\mathrm{p}<0.000$, and $\mathrm{p}<0.05$ in all 3 training sessions in comparison with BT values (Table 3 ). In group B, both BT and AT values were significantly higher at $p<0.005, p<0.000$, $\mathrm{p}<0.000$ in training sessions I and III, respectively, and significantly lower at $p<0.005$ and $p<0.05$ in training session II (Table 3). No statistically significant differences were noted in the remaining trainings.

In group A, AT plasma dopamine increased statistically significantly at $\mathrm{p}<0.005, \mathrm{p}<0.000$, and $\mathrm{p}<0.000$ in all 3 training sessions in comparison with BT values (Table 2). In group B, a significant increase in AT plasma dopamine was found in all 3 training sessions at $p<0.005$, $\mathrm{p}<0.01$, and $\mathrm{p}<0.005$, respectively, in comparison with BT values (Table 3). In group B, statistically significantly higher BT and AT plasma dopamine at $\mathrm{p}<0.05$ and $p<0.01$ were noted in training sessions I and III and significantly lower AT plasma dopamine in training session II at $\mathrm{p}<0.05$ were observed in comparison with the values in group A. No statistically significant differences were seen in the remaining values.

In group A, the analysis of physical fitness showed statistically significant improvement in the results of the following exercises, which were seen in series II: pulling up on the horizontal bar, running for $16.5 \mathrm{~m}$, bends, and ASET at $\mathrm{p}<0.001$ in comparison with the results of series I (Figure 1).

In group $\mathrm{B}$, statistically significant improvement in pulling up on the horizontal bar at $p<0.005$, bends at $p<0.001$, and ASET at $p<0.005$ was found in comparison with series I (Figure 1). An improvement in the results of running for $16.5 \mathrm{~m}$ proved to be insignificant. In both groups, the improvement in the results for shuttle run $10 \times 10 \mathrm{~m}$ was insignificant in series II in comparison with series I (Figure 1).
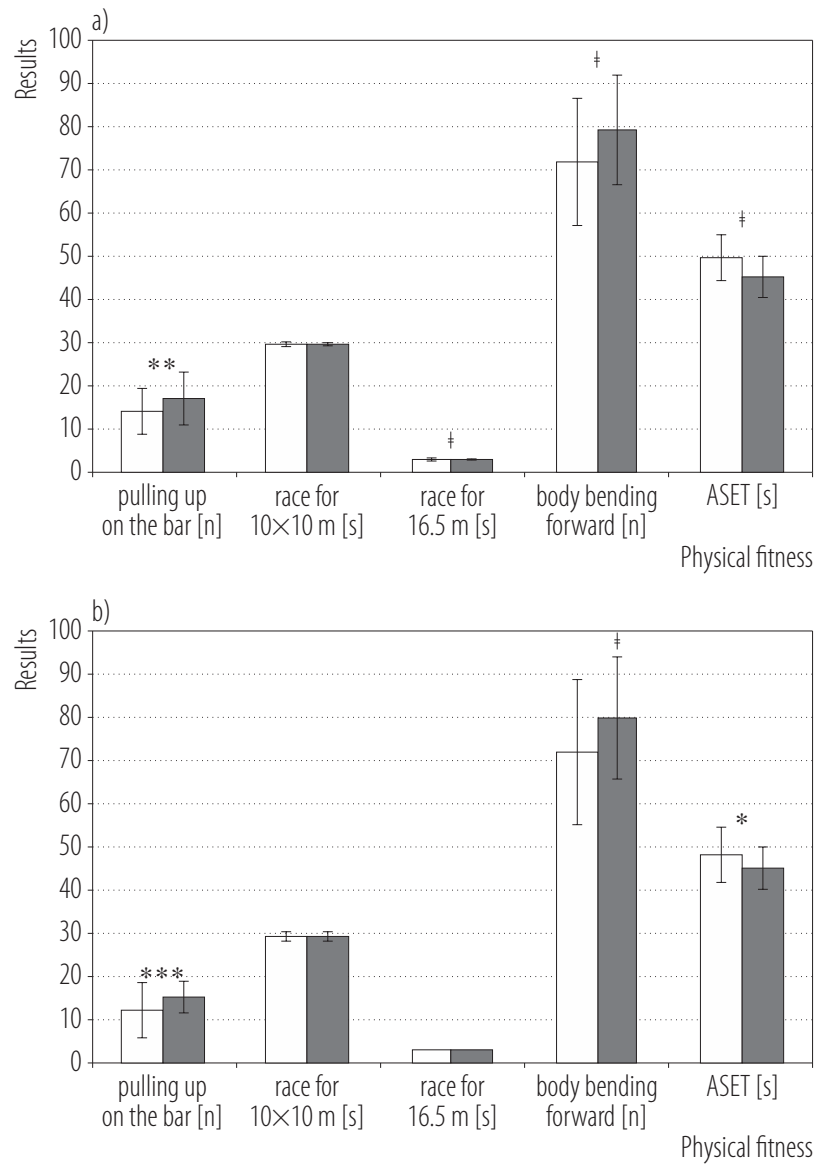

ASET - Aero-Synthetic Efficiency Test.

Different statistical significance in comparison with series I at: $* p<0.05 ; * * p<0.01 ; * *$ * $<0.005 ; \neq p<0.001$.

Fig. 1. Changes of physical fitness in a) group A and b) group B before (series I) and after (series II) completion of the education cycle $[1,10]$

\section{DISCUSSION}

The obtained results showed that the used physical exercises in the case of the examined cadets produced significant AT hormonal changes in both groups, i.e., group A and group B. The difference in these changes resulted from the various exercises intensity and nature, being confirmed by the measured HR values (Table 1). It was shown that the exercise stimulus produced changes in the endocrine system, depending on the intensity and duration of the exercise [11-13]. 
Our study is interesting because the exercises were carried out under aerobic condition of various intensities but the same duration. Moreover, the nature of the SAGI exercises clearly differed from the standard exercises in the control group. The SAGI exercises produced both $+\mathrm{Gz}$ (head-legs direction) and -Gz (legs-head direction) for the cadets, especially during looping. Moreover, the instruments were powered by means of muscles cadets.

The decrease in AT serum cortisol in all 3 training sessions (significant in training session III) observed in our study in comparison with BT values was produced by an aerobic metabolism with predomination of isometric exercises. Used body load for cadets of group A did not exceed compensatory mechanisms in all 3 training sessions. Intervals prior to the consecutive exercises were sufficient $(3 \mathrm{~min}$ ) to return the body to the normal condition. Comparing AT serum cortisol between the groups in all 3 training sessions, one may conclude that the body adaptation was different in the groups, depending on the exercise intensity. Hackney et al. [4] showed that the stimulation of this hormone was higher during anaerobic than in aerobic exercises of similar work volume. It was found that the rate of serum cortisol increased under aerobic conditions depending on the body load but it did not depend on the degree of fitness [14,15]. Changes in BT serum cortisol seen in group B in training sessions II and III indicated that the exercises were intensively performed under aerobic conditions and partially mobilized anaerobic energy sources. Adaptation to the intensity of exercises is adequate to the serum cortisol rise. Such changes in the serum cortisol concentrations were found in the studies by Słowińska-Lisowska and Majda [16,17]. In our study, the decrease in AT serum cortisol was seen in group A in all three training sessions, while it was reverse in group B. Comparing the statistically significant difference between groups in AT cortisol and testosterone in training session II showed higher values of cortisol and lower values of testosterone in group B, and reverse tendency in group A. Observed changes in the concentration of these hormones were consistent with the reports of other authors [18]. The analysis of data in the available literature showed that cortisol levels increased during the load above $60 \%$ maximal oxygen uptake $\left(\mathrm{VO}_{2} \mathrm{max}\right)$ [5-7] or exercise-produced hypoglycemia [19]. In the case of the loads below $50 \% \mathrm{VO}_{2} \max$ of cortisol, concentration could even decrease [5,6]. During the endurance-strength training session, the number of exercise repetitions and intervals duration could influence serum cortisol concentration [20]. Comparing exercises intensity in both groups, one may have assumed that lactate level was lower in group A than that in group B. Therefore, low serum cortisol in group A may have been associated with lower post-exercise lactate concentration. A positive correlation between serum cortisol and lactate level was found [21,22].

It seems that not only the training intensity has the impact on the serum cortisol but also on the type of exercise and body position during the training session. A drop of the serum cortisol may result from the weak adrenals stimulation and also glucose saving as an energy source at the cost of free fatty acids mobilization and use. Lower serum cortisol but preserved physical efficiency indicates that the energy for muscles originates mainly from the free fatty acids and to lesser degree - from glucose. The decrease in insulin levels, the increase in catecholamines and testosterone in both groups indicate high energy expenditure during performance of the training units. Therefore, the decrease in serum cortisol in group A cannot be associated only with low training intensity but also with specificity and intervals between consecutive exercises. Cortisol belongs to the group of hormones which affect protein metabolism, intensifying disintegration of the contractile fibers of the skeletal muscles. In the previous studies with the use of the same training units, effort proteinuria [10] and decrease in serum proteins were shown [23]. The study by Obmiński et al. [24] carried out for 24 cadets trained in 
the human centrifuge of linear characteristics and $+5 \mathrm{Gz}$ (head-legs direction) showed the increase in serum cortisol after training completion.

In our study, both negative and positive accelerations affect cadets in group A during the SAGI training, and the decrease in serum cortisol were seen. It may have suggested that the negative accelerations or negative mixed with positive accelerations may have probably caused the decrease in serum cortisol. Accelerations and changing body position in various planes, resulting from the specificity of the SAGI training may decrease serum cortisol, associated with its passage to the brain. Hormones passage to the brain impedes blood-brain barrier. However, corticosteroids, including cortisol, easily penetrate this barrier because of their lipophilic properties. Their penetration to the brain in hypothalamic area leads to the secretion of the hypophysiotropic hormones within feedback mechanism. The decrease in serum insulin and cortisol may be associated with the increase in growth hormone level on the one hand and stimulation of the sympathetic adrenergic system on the other [25]. Activation of this system aims at saving sources of glucose through the stimulation of triglycerides lipolysis and increased release and utilization of the free fatty acids. In group A, the statistically significant decrease in AT serum cortisol in training session III may result probably from the body adaptation to such specific exercises. In both groups, post-exercise testosterone increases in each series despite of the different physical exercise intensity. Probably it results from the work volume in this study. Both intensity and physical load may exert the impact on serum testosterone [26,27]. It has been shown that sympathetic nervous system plays an important role in the postexercise increase in serum testosterone through indirect stimulation of testes to produce this hormone [28]. It has also been shown that there exists a high positive correlation between post-exercise in testosterone concentration and catecholamines increase [28].
We have shown the increase in serum adrenaline, noradrenaline, and dopamine in both groups, depending on the training intensity. Comparison of catecholamines concentrations has revealed that the stimulation of the sympathetic nervous system is higher in group B than that in group A. In training session III, AT catecholamines increase proportionally to the exercise stimulus in both groups in comparison with BT values. In groups A and B, adrenaline and noradrenaline BT and AT values decrease and dopamine increase in training session III vs. training I, depending on the training intensity, indicating body adaptation to the used load. In the case of healthy individuals, physical exercise and hypoglycemia increase sympathetic nervous system activity and decrease parasympathetic system activity [29]. Insulin secretion decreases [5,7,30], while counterregulative hormones, such as adrenaline, noradrenaline, and cortisol secretion augment [5-7]. Such changes in the hormone concentration have been seen particularly in group B.

As far as the general physical fitness is concerned, it should be stressed that the SAGI training improves motor capabilities of the examined cadets in group A. It is confirmed by a higher number of the events in series II in which statistically significant improvement in the achieved results is obtained in comparison with series I and group B. Comparison of the general physical fitness and cortisol concentration in group A and group B indicates that the lower serum cortisol is, the better physical fitness is. We have noted that in our group A, exercises of the lower intensity with relax pauses may exert the impact on somehow different hormonal profile than that in group B with maintained better physical fitness.

\section{CONCLUSIONS}

The obtained results of this study have shown that the SAGI training scheme decreases AT serum cortisol in all 3 training sessions in group $\mathrm{A}$ in comparison with the control group in which this tendency is reverse. The statistically significant 
difference between group A and group B in AT serum cortisol in training session II and III may indicate the impact of exercise type (besides intensity) on this hormone concentration. The training scheme produces the significant decrease in blood insulin and increase in AT serum testosterone in both groups in all 3 training sessions, depending on the training intensity. The exercises produce statistically significant increase in plasma AT adrenaline, noradrenaline, and dopamine in all 3 training sessions, depending on their intensity. The significant difference between group A and group B in both BT and AT values in training session III indicates that catecholamines are good markers for the assessment of the exercise adaptation level. The SAGI training scheme improves the general physical fitness of the examined cadets in comparison with the control group.

\section{REFERENCES}

1. Wochyński Z, Jędrys R, Stelęgowski A. [Methodology of training on special aviation gymnastic instruments]. Dęblin: Air Force Academy; 2010. p. 43-59. Polish.

2. Banfi G. Hormonal ratio (cortisol:testosterone) as a marker of exhaustion in athletes. J Sports Med Phys Fitness. 1998;38:91-2.

3. Hackney AC, Fahrner CI, Stupnicki R. Reproductive hormonal responses to maximal exercise in endurance-trained men with low resting testosterone levels. Exp Clin Endocrinl Diabetes. 1997;105:291-5, https://doi.org/10.1055/s-0029-1211767.

4. Hackney AC, Premo MC, McMurray RG. Influence of aerobic versus anaerobic exercise on the relationship between reproductive hormones in men. J Sports Sci. 1995;13:305-11, https://doi.org/10.1080/02640419508732244.

5. Bloom SR, Johnson RH, Park DM, Rennie MJ, Sulaiman WR. Differences in the metabolic and hormonal response to exercise between racing cyclist and untrained individuals. J Physiol. 1976;258(1):1-18, https://doi.org/10.1113/ jphysiol.1976.sp011403.

6. Davies CT, Few JD. Effects of exercise on adrenocortical function. J Appl Physiol. 1973;35(6):887-91.
7. Essig DA, Alderson NL, Ferguson MA, Bartoli WP, Durstine JL. Delayed effects of exercise on the plasma leptin concentration. Metabolism. 2000;49(3):395-9, https://doi. org/10.1016/S0026-0495(00)90396-2.

8. Harriss DJ, Atkinson G. Update - Ethical standards in sport and exercise science research. Int J Sports Med. 2011;32(11):819-21, https://doi.org/10.1055/s-0031-1287829.

9. Wochyński Z, Stelęgowski A, Kłossowski M. [Use of AeroSynthetic Efficiency Test in selection of candidates to the Air Force Academy for multirole fighters F-16]. Pol Przegl Med Lotn. 2010;16(4):309-20. Polish.

10. Wochyński Z, Sobiech K. Post-exercise proteinuria in cadets trained on Special Aerial Gymnastics Instruments. Int J Occup Med Environ Health. 2015;28(5):1-11, https://doi. org/10.13075/ijomeh.1896.00454.

11. Guglielmini C, Paolini AR, Conconi F. Variations of serum testosterone concentration after physical exercise of different duration. Int J Sports Med. 1984;5(5):246-9, https:// doi.org/10.1055/s-2008-1025914.

12. Ježowa D, Vigas M, Tatar P, Kvetnanski R, Nazar K, KaciubaUściłko H, et al. Plasma testosterone and catecholamine responses to physical exercise of different intensities in men. Eur J Appl Physiol. 1985;54:62-6, https://doi.org/10.1007/BF00426300.

13. Kjäer M, Secher NH, Bach FW, Sheikh S, Galbo H. Hormonal and metabolic responses to exercise in humans: Effect of sensory nervous blockade. Am J Physiol. 1989;257:95-100.

14. Luger A, Deuster PA, Kyle SB, Gallucci WT, Montgomery LC, Gold PW, et al. Acute hypothalamic-pituitary-adrenal responses to the stress of treadmill exercise. Physiologic adaptations to physical training. New Engl J Med. 1987;316(21): 1309-15, https://doi.org/10.1056/NEJM198705213162105.

15. Oleshansky MA, Zoltick JM, Herman RH, Mougey EH, Meyerhoff JL. The influence of fitness neuroendocrine responses to exhaustive treadmill exercise. Eur J Appl Physiol. 1990;59:405-10, https://doi.org/10.1007/BF02388620.

16. Słowińska-Lisowska M, Majda J. Estimation of the chosen biochemical parameters during training periods in athletes. Biol Sport. 2001;18:225-35. 
17. Słowińska-Lisowska M, Majda J. Immunoglobulin and cortisol concentration in serum the training cycle in track and field athletes. Phys Educ Sport. 2001;1:30-3.

18. Cumming DC, Quigley ME, Yen SS. Acute suppression of circulating testosterone levels by cortisol in men. J Clin Endocrinol Metab. 1983;57:671-3, https://doi.org/10.1210/ jcem-57-3-671.

19. Vranic M, Gauthier C, Bilinski D, Wasserman DEI, Tayeb K, Hetenyi G Jr., et al. Catecholamine responses and their interactions with other glucoregulatory hormones. Am J Physiol. 1984;247(1):E145-56.

20. Kraemer WJ, Dziados JE, Marchitelli LJ, Gordon SE, Harman EA, Mello R, et al. Effects of different heavy-resistance exercise protocols on plasma beta-endorphin concentrations. J Appl. Physiol. 1993;74(1):450-9.

21. Obmiński Z, Klusiewicz A, Stupnicki R. Changes in salivary serum cortisol concentration in junior athletes following exercise of different intensities. Biol Sport. 1994;11;49-57.

22. Obmiński Z, Stupnicki R. Effect of temperature and $\mathrm{pH}$ on magnitude of free fraction of cortisol in serum. Exp Clin Endocrinol Diabetes. 1996;104:350-2, https://doi. org/10.1055/s-0029-1211466.

23. Wochyński Z, Sobiech KA. Effect of exercise on Special Aviation Gymnastics Instruments on blood serum levels of selected biochemical indices in cadets. Ann Agric Environ Med. 2014;21(1):106-11.
24. Obmiński Z, Wojtkowiak W, Stupnicki L, Golec L, Hackney AC. Effect of acceleration stress on salivary cortisol and plasma cortisol and testosterone levels in cadet pilots. J Physiol Pharmacol. 1997;48:193-200.

25. Galbo H. Autonomic neuroendocrine responses to exercise. Scand J Sport Sci. 1986;8:3-11.

26. Duclos M, Corcuff JB, Rashedi M, Fougere V, Manier G. Does functional alteration of the gonadotropic axis occur in endurance trained athletes during and after exercise? A preliminary study. Eur J Appl Physiol. 1996;73:427-33, https:// doi.org/10.1007/BF00334419.

27. Gotshalk LA, Loebel CC, Nindl BC, Putukian M, Sebastianelli WJ, Newton RU, et al. Hormonal responses of multiset versus single-set heavy-resistance exercise protocols. Can J Appl Physiol. 1997;22(3):244-55, https://doi.org/10.1139/h97-016.

28. Fahrner CL, Hackney AC. Effects of endurance exercise on free testosterone concentration and binding affinity of sex hormone binding globulin (SHBG). Int J Sports Med. 1998;19:12-15, https://doi.org/10.1055/s-2007-971872.

29. Galbo H, Christensen NJ, Holst JJ. Catecholamines and pancreatic hormones during autonomic blockade in exercising man. Acta Physiol Scand. 1977;101(4):428-37, https:// doi.org/10.1111/j.1748-1716.1977.tb06026.x.

30. Fushiki T, Wells JA, Tapscott EB, Dohm GL. Changes in glucose transporters in muscle in response to exercise. Am J Physiol. 1989;256(5Pt1):E580-7.

This work is available in Open Access model and licensed under a Creative Commons Attribution-NonCommercial 3.0 Poland License - http://creativecommons.org/ licenses/by-nc/3.0/pl/deed.en. 